\title{
MAIA, MARCUS. (ORG.). PSICOLINGUIÍSTICA E EDUCAÇÃO. SÃO PAULO: MERCADO DE LETRAS, 2018, 258 p.'
}

\author{
Marina Da Silva Cabral \\ Universidade Federal de Santa Catarina, Florianópolis, Santa Catarina, Brasil \\ marina.scabral@hotmail.com \\ Bruno De Azevedo \\ Universidade Federal de Santa Catarina, Florianópolis, Santa Catarina, Brasil \\ bruno_de_azevedo@hotmail.com
}

A relação entre o pensamento e a linguagem, de onde emergem os objetos da Psicolinguística, é, também, vínculo indispensável para os estudos que se debruçam sobre o ensino e a aprendizagem. Esse ponto em comum entre as áreas tende a apontar para uma influência recíproca entre os campos, o que nem sempre se concretiza. Ao publicar Psicolinguística e Educação, Marcus Maia faz um convite - aos próprios autores que dividem a autoria do livro e aos pesquisadores e professores em geral - a essa aproximação tão necessária: levar à Educação, e também trazer dela, contribuições da/para a Psicolinguística. Scliar-Cabral, expoente dessa temática no Brasil, já em 1991, apontava para a importância dos estudos da Psicologia para a Educação, relação que veio a progredir, no campo da linguagem, também com os estudos da Psicolinguística:

\begin{abstract}
Ainda nesse período que antecede a década dos cinquenta, cabe mencionar o surgimento da epistemologia genética de J. Piaget, que deu origem a uma das mais frutíferas escolas em psicolinguística, a escola de Genebra; e a obra de L. Vygotsky, autor soviético [...] conhecido por suas investigações sobre as relações entre pensamento e linguagem ([1934] 1962) (SCLIAR-CABRAL, 1991, p.11).
\end{abstract}

Psicolinguística e Educação se encontra, dessa forma, nessa gama de estudos da Psicolinguística endereçados, principalmente, ao campo da educação linguística. O livro foi publicado pela editora Mercado de Letras no ano de 2018 e organizado por Marcus Maia, professor titular de Linguística da Faculdade de Letras da UFRJ. É um livro altamente recomendado por José Morais, professor emérito da Université Libre de Bruxelles (ULB) e quem assina o prefácio. A obra é composta por oito capítulos de diferentes autores e compromete-se a discutir e lançar luz sob alguns dos problemas principalmente relativos à leitura no âmbito escolar.

O livro organizado por Marcus Maia já conta com uma resenha publicada (FERRARINETO; LEITÃO, 2018) e, em virtude do pioneirismo da obra, aqui revisitamos seus capítulos para ressaltar alguns aspectos da complexa relação entre psicolinguística experimental e educação escolar, os quais merecem ser discutidos em trabalhos futuros, principalmente em relação à formação de professores. Esse é, então, o foco dado ao longo desta resenha: avaliar a proposta do livro tendo em vista a desafiadora formação de professores, principalmente em relação à formação continuada, colocando em relevo, assim, aqueles professores que já atuam na Educação Básica. Considerando, ainda, que Psicolinguística e Educação é o tema do Grupo

\footnotetext{
${ }^{1}$ Agradecemos aos pareceristas da Revista da ANPOLL pelas sugestões e revisões.
} 
de Trabalho de Psicolinguística da ANPOLL nos biênios 2016-2018 e 2018-2020 e que há vários grupos trabalhando em questões específicas levantadas nos capítulos, a proposta de aprofundar a temática da formação de professores face às relações entre psicolinguística experimental e educação escolar visa endossar discussão no âmbito do GT, dando continuidade à interface entre Psicolinguística e Educação sob enfoque da formação de professores.

Scliar-Cabral (2018), sob um enfoque de base neural, é quem abre o livro de forma categórica: apesar de os fatores de ordem socioeconômica afetarem a alfabetização de alunos, "mesmo em situações adversas, é possível alcançar níveis mais altos de aprendizagem" (SCLIAR-CABRAL, 2018, p. 26). Nesse primeiro capítulo, intitulado Inter-relação entre o biológico e o cultural: psicolinguística e educação, a autora argumenta em favor da materialização de um método eficaz e um material didático sólido que sirva de suporte a professores. Depois de sair em defesa de três fatores preponderantes - apropriação científica sólida por parte do professor daquilo que ensina, bom método e bom material pedagógico para melhorar a qualidade da educação em leitura e escrita, Scliar-Cabral discorre acerca da necessária reestruturação das bases epistemológicas da educação, propondo aproximação entre ciências biológicas e humanas.

Ao sinalizar para a necessidade de se reverem os fundamentos epistemológicos da educação, em especial, neste caso, da alfabetização, a autora toma como exemplo os materiais do Pacto Nacional pela Alfabetização na Idade Certa (PNAIC). Segundo Scliar-Cabral, esse material passa ao largo da concepção de conhecimento que emerge da inter-relação entre cérebro e cultura, evocando epistemologia espontaneísta quando se trata de alfabetização. A autora formula, assim, a tese de que se precisa ensinar - por exemplo, os princípios do Sistema de Escrita Alfabética (SEA) - para que o sujeito aprenda, por meio de métodos consolidados, a ler e a escrever, considerando, dessa forma, a necessária relação, para o ensino, entre o biológico e o cultural.

A partir dessas constatações é que são apresentadas possíveis contribuições da Psicolinguística para o traçado das políticas públicas em educação, considerando-se que tais contribuições devam partir de base epistemológica que toma o conhecimento como resultado da interação entre aquilo que é inato - o aparato biológico - e aquilo que decorre da experiência - os fatores culturais. Ao fundamentar-se epistemologicamente nesta base, Scliar-Cabral aponta para tópicos fundamentais estudados pela Psicolinguística e que podem contribuir para a alfabetização. A autora divide essas questões em subseções do capítulo, que são distribuídas em: noção de input e output, recepção - tanto oral como pela via de leitura - e produção, consciência fonológica e fonêmica, processamento na leitura e na produção escrita, fases no processamento da leitura e modelo psicolinguístico de produção escrita - com base em Garman (1990).

Embora o capítulo pareça focar no que é do âmbito do biológico como condição para melhorar a qualidade do ensino - parecendo se aproximar, assim, dos estudos de base neural, como o conexionismo e as neurociências -, o que a autora propõe, de fato, é a reformulação das bases que norteiam as políticas públicas em alfabetização pela via da inter-relação entre o biológico e o cultural, condição cara aos estudos da epistemologia genética, como a abordagem histórico-cultural.

O segundo capítulo, intitulado Teoria da Testagem, experimentos psicolinguísticos e a avaliação das habilidades de leitura e escrita, é de autoria de Luiz Amaral. O autor reconhece, logo na introdução, que fatores socioeconômicos podem caracterizar obstáculos intransponíveis para a aprendizagem de leitura e escrita, mas, apesar dessa declaração, Amaral (2018) discute, ao longo de todo o capítulo, as questões de letramento a partir de uma perspectiva cognitiva, fundamentado na Teoria da Testagem (TT). Nas primeiras seções, o autor traz explicações acerca de conceitos caros à teoria - como construto, instrumento de testagem, critério de 
avaliação e tipos de validade -, além de tratar da importância de os instrumentos desenvolvidos a partir da TT passarem reiteradamente por processos de validação.

Já nas duas últimas seções, intituladas Exemplos de habilidades para o letramento pleno e Experimentos Psicolinguísticos e o Letramento, respectivamente, Amaral (2018) dedica-se a discutir algumas habilidades elencadas por ele e com base em Tankersley (2003) como importantes para um leitor eficiente. São elas: consciência fonológica, decodificação fonológica, vocabulário, fluência, compreensão e pensamento de ordem superior. Posteriormente, levando em conta as habilidades citadas para propostas de inserção pedagógica, o autor aborda a inserção de técnicas experimentais em contexto de sala de aula, tais como 'tempo de reação em testes de gramaticalidade', 'imitação induzida' e 'rastreamento ocular'.

O que o autor propõe, assim, ao longo do capítulo, são métodos avaliativos que sejam capazes de revelar de que maneira os alunos aprendem, de modo que os resultados auxiliem no processo de ensino e de aprendizagem da modalidade escrita da língua. Para isso, lança mão da psicolinguística experimental e, nesse âmbito, da Teoria da Testagem, em diálogo com questões relativas ao letramento, buscando estabelecer relação entre quesitos para o letramento pleno e dados decorrentes de experimentos psicolinguísticos.

Ao elencar técnicas experimentais como forma de auxiliar professores a encontrar respostas quanto ao ensino e à aprendizagem de leitura e escrita, Amaral (2018, p. 72) considera que "o mais importante é entender o objetivo da proposta [...] e não necessariamente usar as ideias específicas [...] como exemplos únicos a serem usados”. O autor ressalta, portanto, a importância da adequação de suas propostas ao contexto real de ensino, sendo cauteloso ao propor técnicas que não sejam implementadas de forma vertical, mas que considerem o entorno social dos sujeitos que ensinam e que aprendem. Amaral (2018) parece fazer jus a um caro pressuposto dos estudos fundantes do campo do letramento - como Kleiman (1995) e Street (2003) -: o olhar atento para contextos socioeconômicos diversos para posterior proposta de atuação. Seu movimento vai ao encontro, assim, do objetivo traçado no capítulo: o diálogo entre conceitos centrais em letramento e em psicolinguística experimental.

Kenedy (2018) é o autor do capítulo O problema do analfabetismo funcional no Brasil sob uma análise psicolinguística. Como aponta o título, o autor trata, nesse terceiro capítulo, de uma das questões que sempre esteve presente na agenda da alfabetização brasileira: o analfabetismo funcional. Na introdução, Kenedy (2018) disserta sobre a condição da educação no país a partir de instrumentos de avaliação, os quais atestam, segundo o autor, evidente subletramento de parte significativa dos estudantes. A partir disso e reconhecendo as possíveis causas para o fracasso educacional - bastante relacionadas aos aspectos sociais -, Kenedy se propõe a tratar de fenômeno psicolinguístico que estaria entre as razões pelas quais alguns estudantes brasileiros não se inserem na cultura letrada: o status cognitivo da diglossia, que geraria diferença em nível de língua entre as variedades do uso vernáculo brasileiro e a escrita culta que circula entre os diferentes gêneros do discurso.

Nas seções que seguem, o autor disserta sobre o histórico da educação no Brasil, elaborando, a partir disso, a hipótese de que "para essa multidão em alguma medida analfabeta, a escrita do padrão culto formal (ou mesmo a oralidade culta do mundo letrado) provavelmente assume o caráter cognitivo de segunda língua" (KENEDY, 2018, p. 91). Para corroborar a hipótese, o autor cita o Bilinguismo Universal e a Teoria das Múltiplas Gramáticas. Kenedy (2018) apresenta a diglossia, assim, como um dos fatores que dificultam a efetiva consolidação do alfabetismo pleno de estudantes.

Tal fenômeno psicolinguístico de que trata o autor ao longo do capítulo diz respeito ao caráter cognitivo de segunda língua que a escrita do padrão culto formal assumiria para estudantes "em alguma medida analfabetos" (KENEDY, 2018, p. 91). Ao partir dessa constatação, o autor propõe que a modalidade formal da escrita seja ensinada por meio de 
metodologia adequada, que encare o uso vernáculo como a primeira língua, com seu léxico e gramática diferentes do que seria a segunda língua (modalidade formal).

Como proposta de enfrentamento ao problema, Kenedy (2018) apresenta projeto de pesquisa em fase de desenvolvimento pelo Grupo de Pesquisa em Linguística Teórica e Experimental da Universidade Federal Fluminense (GEPEX). Trata-se de estudo que investiga a mencionada diglossia entre o vernáculo de estudantes de camadas populares e a escrita formal padrão, tendo como objetivo último a formulação de uma gramática pedagógica que auxilie na prática docente e na produção de materiais didáticos. Os resultados preliminares do estudo "sugerem que a estruturação do período parece ser a principal diferença sintático-discursiva que opõe a produção de textos orais e escritos no vernáculo de estudantes de origem popular e na escrita formal do padrão culto" (KENEDY, 2018, p. 96). Segundo a investigação, que contou com análises de redações do ENEM e com entrevistas orais com estudantes de escolas públicas, há preferência, na produção linguística vernacular dos estudantes desprivilegiados economicamente, por estruturações sem conjunção, distribuídas de forma linear temporal ou lógica e com poucas subordinações entre as orações. Entendemos que essas conclusões podem ser derivadas da interpretação dos dados orais, mas ressaltamos que não há como saber, pela produção escrita do ENEM, se os alunos que têm preferência pela parataxe na construção do período são, de fato, estudantes das classes populares, uma vez que o Exame Nacional do Ensino Médio é um requisito importante para ingresso em universidades públicas do país, sendo realizado tanto por estudantes de origem popular como por aqueles da classe privilegiada economicamente ${ }^{2}$.

O quarto capítulo é da autoria de Marcus Maia e recebe o título Computação estrutural e de conjunto na leitura de periodos: um estudo de rastreamento ocular. De forma bastante didática, lançando mão de analogia entre as peças de um motor de carro e a linguagem, Maia (2018) elucida, na introdução, no que consiste uma estrutura para, mais à frente, explicar um fenômeno recorrente nas escolas: apesar de se ensinar sobre as estruturas gramaticais em seu caráter terminológico, não se garante a eficácia de seus usos. O autor menciona que, a despeito de a Psicolinguística avançar cada vez mais em termos de elucidação de como as estruturas gramaticais são processadas na mente humana, tais conhecimentos científicos "ainda não impactaram como deveriam uma dimensão importante da vida social: a educação escolar" (MAIA, 2018, p. 104). A consideração mencionada endossa o objetivo do livro organizado pelo autor do capítulo: aproximar o conhecimento produzido pela ciência da cognição da linguagem e professores de língua da Educação Básica, em um esforço de contribuir para a reversão do cenário brasileiro atual em termos de leitura e escrita, o qual é apresentado de forma minuciosa nos capítulos de Scliar-Cabral e Kenedy.

Uma das ações mencionadas por Maia (2018) e que vai ao encontro do objetivo do livro é a Rede Nacional de Ciência para a Educação, que visa estreitar o laço entre aquilo que é produzido na academia e a realidade escolar. Estudos atrelados a essa iniciativa vêm demonstrando, segundo o autor, que o ensino de leitura e escrita no ambiente escolar tem se resumido à prescrição e nomenclatura dos itens da língua. Tal fato vem criando fenômenos em que os estudantes são capazes de identificar e nomear as estruturas linguísticas, mas não conseguem se utilizar de tais estruturas para articular a compreensão e escrita de textos.

Depois de problematizar as questões apontadas acima, o autor apresenta estudo experimental que aponta a defasagem na computação de estruturas oracionais nos períodos como uma das razões para a dificuldade de leitura dos estudantes em nível fundamental. Depois

\footnotetext{
${ }^{2}$ Essa afirmação decorre da normatização de não identificação dos estudantes nas provas do ENEM. Ainda assim, ressaltamos que não tivemos acesso ao estudo que está em andamento, o qual pode ter conseguido, junto ao INEP, permissão de análise das produções escritas de determinadas escolas públicas.
} 
de justificar a pesquisa experimental a partir da perspectiva psicolinguística fundada no rastreamento ocular, Maia (2018) descreve minuciosamente o estudo, cujos resultados caracterizam o tipo de leitura dos grupos analisados: alunos do oitavo ano do ensino fundamental e alunos de curso superior em Letras.

As conclusões preliminares do estudo indicam que enquanto os estudantes de ensino superior mantêm a fixação ocular por mais tempo na oração principal, o que permite leitura mais completa, os estudantes do oitavo ano do ensino fundamental mantêm padrão visual guiado pela ordem de apresentação das estruturas, e não pelo tópico do período, de forma que o tempo médio de fixação não é maior na oração principal, mas nas subordinadas, quando estas são apresentadas primeiro. Tal comportamento incide em leitura desengajada, já que ao dispensarem mais atenção aos primeiros períodos, independentemente de serem ou não o período principal, não conseguem compreender a ideia principal do que está sendo lido, o que causa desinteresse ao longo da leitura linear e incide em "queda significativa no índice de acerto nas questões interpretativas" (MAIA, 2018, p. 127). A partir das constatações derivadas do estudo experimental, o autor sugere que se introduzam rastreadores oculares nas escolas, a fim de despertar nos estudantes uma 'consciência leitora'. Apesar de parecer ser, como Maia nomeia, uma prática inovadora, precisaria estar aliada à formação de professores quanto à utilidade de se entender como se lê para contribuição efetiva no processo de aprendizagem de leitura, de modo que se entenda as razões pelas quais se introduziria o laboratório científico na sala de aula.

No quinto capítulo, sob o título Compreensão multimodal e rastreamento ocular na leitura de gráficos, Rodrigues, Fragoso e Ribeiro (2018) abordam como o processo de leitura de gráficos ocorre, com enfoque especial na metodologia de rastreamento ocular, aquela utilizada no estudo de Maia (2018). Logo na apresentação do capítulo, os autores ressaltam a importância de que professores de todas as áreas saibam conduzir a leitura de material multimodal, identificando, para isso, as dificuldades dos alunos e desenvolvendo estratégias que incidam na habilidade de compreensão textual. Para isso, tais professores precisam ter a compreensão de que tanto as informações verbais como as não-verbais precisam ser trabalhadas, já que, em material multimodal, elas se apresentam de forma integrada.

As seções que seguem são dedicadas à história do gênero 'gráfico' e aos seus componentes estruturais. Os autores fornecem, assim, apresentação amplamente didática acerca da configuração do gênero: abordam desde questões estruturais básicas (e.g. eixos X e Y), passando pela história dos criadores dos diversos tipos de gráficos, até questões mais práticas de sua construção, o que envolve estudos sobre o processamento da informação visual no cérebro humano. Os autores exploram, a partir disso, os oito princípios de construção de gráficos, com base em Kosslyn (2006). São eles: princípio da relevância, princípio do conhecimento apropriado, princípio da saliência, princípio da discriminação, princípio da organização perceptual, princípio da compatibilidade, princípio das alterações informativas e princípio das limitações de capacidade. Todos eles devem ser considerados na elaboração de gráficos para que se facilite a compreensão leitora.

Na seção A compreensão de gráficos os autores se dedicam a explorar, a partir de base cognitiva, questões "desde o processo de percepção dos estímulos visuais presentes em gráficos a processos de alta ordem relativos a como as informações extraídas de gráficos são representadas e integradas a nossas bases de conhecimento" (RODRIGUES et al., 2018, p. 146). Esses processos cognitivos são abordados apenas sob a visão de Pinker (1990). Em seguida, são explorados resultados de experimentos que utilizaram a técnica de rastreamento ocular para leitura de gráficos e compreensão multimodal de constelações gráfico-texto.

No entanto, é em sua proposta de buscar entender como ocorre o processo de integração de informações contidas no texto e em gráficos, como a leitura multimodal se dá, e 
quais fatores podem apresentar custos para o processamento multimodal que os autores trazem uma contribuição para a área de psicolinguística e educação. Para sermos mais específicos, os autores se propõem a demonstrar como os aspectos supracitados, uma vez ao alcance de professores de diversas disciplinas, podem contribuir para que estes trabalhem estrategicamente para auxiliar seus alunos.

A relação entre gráficos e educação ocorre somente na última seção - a menor do capítulo. Entretanto, não há aprofundamento suficiente, o que pode ser problemático, considerando a proposta do livro de estabelecer um diálogo entre Psicolinguística e Educação. Embora os autores não explorem detalhadamente a relação entre a importância da leitura de gráficos e a educação, o capítulo fornece um considerável material de apoio acerca da estrutura do gênero gráfico, o que pode ser utilizado como subsídio para seu ensino. O texto se aproxima, assim, de um material didático de apoio ao professor tratando da perspectiva psicolinguística sobre a compreensão multimodal de gráficos.

O sexto capítulo do livro, de Mota, Mascarello e Buchweitz, sob o título Memória de trabalho e dificuldades de aprendizagem da leitura no $2^{\circ}$ ano do Ensino Fundamental: os resultados de uma intervenção, traz breve apresentação de dados referentes ao insucesso escolar. Os autores se propõem, a partir desse quadro, a focar no fator 'dificuldades de aprendizagem na leitura', ressaltando que a otimização da memória de trabalho (MT) está relacionada ao bem estar dos indivíduos ao longo tanto da vida escolar quanto em outros domínios. Em outras palavras, a melhora na leitura influencia diretamente no sucesso escolas das crianças. Por fim, e mais importante, os autores destacam que ao obter sucesso na aprendizagem da leitura, outros aspectos da vida são beneficiados, como "bem-estar social e emocional" dos indivíduos (MOTA et al., 2018, p. 175)

Depois de elucidarem, com base na psicologia cognitiva, no que consiste a memória de trabalho, passando pela explicação de outros sistemas de memória - sensorial, curto prazo e longo prazo -, os autores apresentam descrição detalhada dos procedimentos experimentais para aplicação de intervenção pedagógica a fim de ampliar a capacidade de MT das criançasparticipantes do estudo abordado. Os autores explicam que essas atividades são elaboradas com "materiais de baixo custo, são relativamente simples de serem aplicadas [...], podendo ser usadas diariamente, e não exigem planejamento exaustivo do professor nem formação específica para execução" (MOTA et al., 2018, p. 186). Ao utilizar materiais de baixo custo e fácil elaboração, os autores se mostram engajados na aproximação da psicolinguística com a educação.

O estudo realizado por Mota e colegas, de natureza intervencionista, obteve resultados otimistas, no sentido de que a intervenção aplicada teve efeito sobre a capacidade de memória de trabalho dos alunos influenciando positivamente a leitura dos participantes. Os resultados obtidos levaram os autores a concluírem que a capacidade de memória de trabalho de estudantes pode ser alvo de aprimoramento por meio do uso de estratégias. É importante ressaltar o resultado positivo que a intervenção aplicada aos autores teve na motivação dos estudantes. Mota e colegas evidenciam que "à medida que a ação interventiva foi sendo implementada, percebe-se que o comportamento de passividade e timidez foi aos poucos sendo substituído por um comportamento mais participativo", que por conseguinte reverberou na rotina da sala de aula (MOTA et al., 2018, p. 189). A partir desse trecho, destacamos que tal ação foi inspiradora, como Maia pretendia com a obra, assim expresso no prefácio.

Portanto, o estudo de ação intervencionista de Mota e colegas está alinhado com a proposta do livro de aliar Psicolinguística e Educação, pois não são raras as vezes em que os pesquisadores são ambiciosos no que se refere à implementação de seus achados na realidade escolar. Neste caso, os autores reconhecem a realidade educacional brasileira e direcionam seu 
estudo para que o/a professor(a) brasileiro(a) possa auxiliar seus alunos com dificuldades na habilidade de leitura.

No sétimo capítulo, intitulado Neurociências, Psicolinguística e Aprendizagem de Línguas Adicionais: um diálogo necessário no contexto da educação do século 21 , as autoras Finger, Brentano e Fontes debatem o contexto multilíngue em que estamos inseridos, ressaltando os benefícios do aprendizado de línguas adicionais, como "o desenvolvimento de habilidades cognitivas de domínio mais geral, que extrapolam o domínio linguístico, como as funções executivas, a memória e a atenção" (FINGER et al., 2018, p. 200). O capítulo está disposto, assim, de forma a explicitar como a Psicolinguística e as Neurociências podem contribuir para a aprendizagem de línguas adicionais em contexto escolar. Vale mencionar que, ainda nessa seção introdutória, as autoras desmistificam a ideia de status monolíngue do Brasil, através de dados que suportam a afirmação de que somos uma nação multilíngue, com o emprego de mais de 330 línguas, entre línguas indígenas e de imigração, além da Língua Brasileira de Sinais (LIBRAS).

$\mathrm{Na}$ segunda seção, intitulada $A$ contribuição das neurociências, Finger e colegas evidenciam as contribuições das Neurociências para a compreensão da organização do cérebro e das bases neurais da aprendizagem, aprofundando, a partir disso, o debate acerca do papel das funções executivas na cognição humana - inibição, memória de trabalho e flexibilidade cognitiva, baseadas em Diamond (2013), assim postas por Finger et al. (2018). As autoras abordam, ainda nessa seção, o aprendizado de língua adicional (LA) na infância como fator que pode influenciar no desenvolvimento dessas funções executivas, conectando, portanto, tais funções com o bilinguismo.

$\mathrm{Na}$ terceira seção do capítulo, as autoras foram bem-sucedidas ao explicar, de forma resumida e didática, as contribuições da Psicolinguística para a aprendizagem de línguas adicionais, explicitando sua função de elucidar "a dinâmica de interação das línguas no cérebro de um aprendiz de LA ou falante bilíngue" (FINGER et al., 2018, p. 205). Além do mais, elas apresentam noção clara da interatividade das línguas, esclarecendo que a língua materna interage com as línguas adicionais e desmistificando a noção prévia de que a aprendizagem de outras línguas seria prejudicial à língua materna. Ao contrário, as autoras explicam que além da influência da língua materna na LA, o processamento da L1 é influenciado pela LA.

Por fim, na seção que antecede as considerações finais, intitulada $O$ diálogo necessário no ensino de língua adicional, Finger e colegas discutem a necessidade de as pesquisas em Neurociências e Psicolinguística comunicarem-se com a Educação, já que podem contribuir para "o trabalho prático de professores no desenvolvimento de estratégias pedagógicas que estimulem o processo de aprendizagem de LA e o tornem mais eficaz" (FINGER et al., 2018, p. 210). As autoras citam, então, alguns exemplos de como isso pode ocorrer, o que parece contribuir para a proposta do livro, que visa o diálogo entre Psicolinguística e Educação. Parecenos que, apesar de o esforço genuíno das autoras contribuir para o ensino de LA no contexto das Neurociências e da Psicolinguística em diálogo com a Educação, essas estratégias esbarram na formação inicial e continuada de professores, que têm se mostrado insuficientes em se tratando de tais áreas. Esse esforço, para que se efetive em ações na escola, parece ter que extrapolar a produção científica, inserindo-se nos programas de formação continuada das redes de ensino.

No oitavo e último capítulo do livro, sob o título Cérebro e leitura: educação, neurociência e o novo aluno da era do conhecimento, as autoras França, Lage, Gomes, Soto e Gesualdi-Manhães, depois de explorarem dados sobre o analfabetismo funcional no Brasil, indicam que a situação, já alarmante, pode piorar no contexto das novas tecnologias. Por esse motivo, trazem debate sobre uma espécie de 'novo aluno', aquele da era tecnológica atual e como este é caracterizado em termos cognitivos. Nessa perspectiva, as autoras argumentam que 
as escolas precisariam entender melhor esse 'novo aluno', para então contribuir para sua aprendizagem. O papel do professor, nessa perspectiva, parece ser secundarizado, uma vez que as autoras defendem que "os alunos sejam os agentes de seus próprios processos de aprendizagem para evitar a não adesão às atividades sob a forma de erros de distração, impulsividade, letargia e resistência a seguir comandos em situações de rotina" (FRANÇA et al., 2018, p. 226). As novas demandas cognitivas, sob esse prisma, parecem exigir da escola uma postura em que o relativismo ganha corpo, já que o 'novo aluno' e suas novas necessidades são centrais no processo. Parece-nos que, em uma tentativa de distanciamento da Escola Tradicional, tal proposta aproxima-se sobremaneira à Escola Nova, na qual aluno e seu interesse são o centro do trabalho educativo, ficando professor e conteúdos secundarizados (SAVIANI, 2012 [1983]).

Em seguida, na seção A leitura como uma ferramenta essencial na Era do Conhecimento, as autoras explicam, com uma gama exaustiva de exemplos, que a leitura é fundamental para que o 'novo aluno' possa aderir às novas tecnologias. Na seção que segue, apesar de ter como título $O$ processo de aquisição de leitura, as autoras não descrevem como ocorre esse processo - o que é feito, de fato, na seção seguinte -; ao invés disso, tecem algumas comparações acerca da naturalidade da aquisição da fala (sem mencionar a compreensão auditiva) em comparação à aquisição da escrita e da leitura, ambos processos que requerem instrução formal. Na seção A leitura sob o ponto de vista da Neurociência, França e colegas trazem a contribuição de Dehaene (2005) para a área.

Além disso, as autoras se propõem a trazer, na seção seguinte, discussão sobre métodos de alfabetização. Entretanto, citam apenas que o método global é o mais empregado no Brasil e saem em defesa do método fônico, sem entrar nos princípios dos métodos para explicitar tal escolha. Dado o enfoque do capítulo e a proposta do livro - de ser instrumento que contribua para melhorar as competências linguísticas dos alunos do país -, a alfabetização, tema caro aos estudos que abarcam leitura e escrita, poderia ter sido explorada de forma menos resumida, contando com mais parágrafos explicativos para que pudesse servir, de fato, à reflexão de professores em formação ou que já estão em sala de aula. Outra possibilidade seria, a nosso ver, citar estudos que se debruçam sobre o assunto e que indicam a manutenção do método fônico, como Morais (2006) e Sebra e Dias (2011), em uma forma de possibilitar ao leitor/professor contato mais efetivo com assunto crucial para o sucesso no desenvolvimento da leitura e da escrita.

Nas demais seções do capítulo, as autoras descrevem procedimentos experimentais utilizando potenciais bioelétricos relacionados a um evento - a leitura - para diferenciar bons leitores daqueles que deduzem e/ou adivinham porções do texto. Ao fazer isso, França e colegas estabelecem uma conexão entre pesquisa em Psicolinguística e em Educação, propondo transposição desses procedimentos para que a prática educacional possa (idealmente) ser remediada no que se refere a alunos com dificuldades de leitura.

A partir do estudo dos capítulos da obra, entendemos que Psicolinguística e educação revela-se como livro importante na colaboração para formação de professores de língua, já que todos esses capítulos apresentam, em alguma medida, estudos que procuram estabelecer relação entre as contribuições das pesquisas em Psicolinguística e o ensino e a aprendizagem de leitura. O livro parece procurar estreitar os laços entre os saberes produzidos na esfera acadêmica e a realidade escolar, contribuindo para aquilo que é, ainda, desafio em termos de educação no país: letramento pleno e alfabetização.

Concluímos, dessa forma, que Psicolinguística e educação entra para o rol de livros necessários à formação do professor, partindo da compreensão de que o estudo do processamento da linguagem tem muito a contribuir para o ensino e a aprendizagem de língua e, dentro desse quadro, para a compreensão leitora, foco do livro organizado por Marcus 
Maia. Ainda, projetamos que trabalhos futuros, possivelmente derivados de discussões empreendidas no âmbito do Grupo de Trabalho de Psicolinguística da ANPOLL, possam aprofundar os temas abordados em Psicolinguística e Educação, tomando como foco a formação de professores, já que esta é uma dimensão essencial para que projetos de aproximação entre educação escolar e resultado de pesquisas acadêmicas efetivem-se, de fato, em ações fecundas. Apenas com um projeto de formação adequada àqueles que estão no dia a dia escolar é que se pode pensar no sucesso das ações tão bem elaboradas em Psicolinguística e Educação.

\section{REFERÊNCIAS}

DEHAENE, S. Reading in the Brain: The Science and evolution of a human invention. Viking, Ed. Nova York: Penguin Books, p. 400. 2005.

DIAMOND, A. Executive Functions. Annual Reviews Psychology, v. 64, pp. 135-168. 2013.

FERRARI-NETO, J.; LEITÃO, M. M. Resenha do livro Psicolinguística e Educação. Revista da Abralin, v. 17, n. 1, 2018.

GARMAN, M. Psycholinguistics. Cambridge: Cambridge Univ. 1990.

KLEIMAN, A. (Org.). Os significados do letramento: uma nova perspectiva sobre a prática social da escrita. Mercado de Letras, 1995.

KOSSLYN, S. M. Graph design for the eye and mind. Nova York: Oxford University Press. 2006.

MAIA, M. (Org.). Psicolinguística e Educação. São Paulo: Mercado das Letras, 2018, 258 p.

MORAIS, A. G. Concepções e metodologias de alfabetização: por que é preciso ir além da discussão sobre velhos "métodos"? Brasília, DF: Secretaria de Educação Básica. Trabalho apresentado no Seminário Alfabetização e Letramento em Debate. 2006.

PINKER, S. A theory of graph comprehension. In: FRIEDLE, R. (ed.) Artificial intelligence and the future of testing. Norwood: Ablex, pp. 73-126. 1990.

SAVIANI, Dermeval. Escola e democracia. 42. ed. Campinas, SP: Autores Associados, 2012 [1983].

SCLIAR-CABRAL, L. Histórico sobre a psicolinguística. In: SCLIAR-CABRAL, L. Introdução à Psicolinguística. São Paulo: Ática, 1991.

SEBRA, A. G.; DIAS. N. M. Métodos de alfabetização: delimitação de procedimentos e considerações para uma prática eficaz. Rev. Psicopedagogia, v. 28, p. 306-320. 2011.

STREET, B. Abordagens Alternativas ao Letramento e Desenvolvimento. Teleconferência Unesco Brasil sobre 'Letramento e Diversidade', 2003. 
TANKERSLEY, K. Threads of Reading: Strategies for Literacy Development. Alexandria, Va: Association for Supervison and Curriculum Development. 2003.

Recebido em: 31 de janeiro de 2020

Aceito em: 04 de abril de 2020

Publicado em Maio de 2020 